Review Articles

\title{
A Review of Human Induced Vibrations on Footbridges
}

\author{
${ }^{1,2}$ C. Maraveas, ${ }^{2}$ Z.C. Fasoulakis and ${ }^{3}$ K.D. Tsavdaridis \\ ${ }^{I}$ School of Mechanical, Aerospace and Civil Engineering, University of Manchester, UK \\ ${ }^{2}$ C. Maraveas Partnership-Consulting Engineers, Athens, Greece \\ ${ }^{3}$ Institute for Resilient Infrastructure, School of Civil Engineering, University of Leeds, UK
}

Article history

Received: 21-07-2015

Revised: 08-08-2015

Accepted: 03-10-2015

Corresponding Author:

C. Maraveas

School of Mechanical, Aerospace and Civil Engineering, University of Manchester, UK

Email: c.maraveas@maraveas.gr

\begin{abstract}
An extensive literature review of human induced vibrations that flexible footbridges experience is addressed in this study. Qualitative information is comprehensively included herein to provide common methods and code recommendations for the practicing engineers. The parameters affecting the dynamic response of footbridges excited by pedestrians are highlighted. In particular, the synchronous lateral excitation is addressed. This investigation can be valuable for the design criteria selection. In addition, this work contributes to the review of numerous case studies correlating important dynamic characteristics for various footbridge structural types, the variability of which confirms the complexity of the issue. Furthermore, vibration upgrading methods are described, focusing on applications of tuned mass dampers and remarkable conclusions are drawn.
\end{abstract}

Keywords: Footbridges, Human-Induced Vibrations, Dynamic Instabilities, Human-Structure Interaction, Vibration Upgrading

\section{Introduction}

Since the beginning of the millennium, observed dynamic instabilities on footbridges induced by human vibrations have attracted considerably more researchers. Although the capacity of a structure is of paramount importance, the design of footbridges has been focused on the serviceability state. Modern design is implemented towards lighter, flexible and slender structures, in a way that comfortability, safety and the social aspect with regards the pedestrians have to be considered. The last observation introduces several interaction phenomena making the issue especially complex. The problem of excessive vibrations was especially highlighted in recent years, since some footbridges were laterally excited Synchronous Lateral Excitation (SLE) by large crowds which interact with the natural vibration of the bridge and act as negative dampers, causing unacceptable discomfort (serviceability failure). For a comprehensive description of the phenomenon the reader is referenced to Dallard et al. (2001).

The phenomenon of human induced vibrations and the interaction with the natural inherited vibrations of the structure has occupied the field of biomechanics as well. A major comprehensive review that bridges the gap between biomechanics of human gait and civil engineering dynamics is addressed by Racic et al.
(2009). Indirect measurement methods of humaninduced loading, combining visual motion tracking systems and known body mass distribution, implemented by anthropometry and kinematics of body segments, are also included therein, providing information about the distribution of body mass. Furthermore, uncertainty issues regarding the structural vibrations are especially highlighted in order to stress the necessity of new simulation models for investigation.

A main characteristic of the dynamic interactions is regarded the sudden instability phenomena with a small alteration of the effective parameters, for instance due to the increase of the number of people crossing a footbridge. This observation has been verified through both experimental and theoretical studies.

The fundamental elements that need to be determined during the optimized design of a laterally unrestrained footbridge are considered as: (a) The induced loadings which indicate the real loading conditions for the appropriate simulation and (b) the stability criteria, that define the safety of the structure according to the serviceability limits. Therefore, advanced simulation of load models should be adopted, the reliability of which should be validated against full-scale testing. In the last decade, many tests have been conducted investigating both the human induced loads and the response of the various types of bridge decks. 
Among the parameters that affect the dynamic response of the structural system of a footbridge under human vibrations are regarded: The density of the crowd, the type of users, the users activity-such as walking, running, etc. (active human) or standing (passive human), even the visual characteristics. It has been observed that the same user behaves in significant different way (dissimilar comfort) crossing bridges with the same dynamic properties, yet of different type and surrounded by different landscapes (JRC/ECCS, 2009). The latter last phenomenon implies the factor of vibration expectancy.

Two types of interactions have been recorded according to the literature (Pedersen, 2013), namely the interaction between human-structure and the interaction between humans. An important benchmark towards the modeling of the aforementioned interactions is implemented by Nakamura's load model (Nakamura, 2004), which implies that the pedestrians adjust their walking trend when the bridge velocity becomes large. Particularly regarding the interaction between humans, there is almost a linear decrease of the walking speed along with the increase of the crowd density that has been reported in several studies (De Donno et al., 2005; Venuti and Bruno, 2007; 2009; Butz et al., 2005), while in other studies (Dallard et al., 2001) it has been observed that the lateral forces are reduced when above 1.7 walkers $/ \mathrm{m}^{2}$. This phenomenon is attributed to the restriction of the space while the crowd becomes denser. Furthermore, it has been observed that the visual contact has an impact on the resulting response (Racic et al., 2009; Bocian et al., 2012).

There are also two types of receivers on a footbridge: The pedestrian (moving) and the passive person (standing). It has been found that the passive person affects both the damping and the natural frequency of the bridge, while the acceleration response of each one is expected to be different. In addition, the presence of the passive receiver is recommended for a more realistic estimation of the serviceability comfortability, although the bridge response can be significantly reduced (Pedersen, 2013). Regarding the current codes of practice (JRC/ECCS, Sétra), the influence of the static pedestrian mass corresponding up to $5 \%$ of the bridge mass can be ignored, since it results in the decrease of the natural frequency by lower than $2.5 \%, f^{\prime}=f / \sqrt{1.05}$.

It is obvious that the considerations mentioned above amplify the complexity of the problem, for which the relevant codes of practice do not provide efficient design guidelines until recently (while the quantification of the results is still under investigation). This work focuses on the clarification of the existing design procedures, after a thorough presentation of the influencing factors and the alternative load models.
Moreover, a few case studies are reviewed, while the effects of the damping modifications are highlighted.

\section{Predicting Methods}

Two ways of estimating the actions of pedestrians walking are considered in the literature (Pedersen and Frier, 2013); namely the use of deterministic loads, which do not take into account the stochastic nature of the walking load introduced by the walking parameters and the use of stochastic models, which implies a more advanced approach for computing the bridge response. Among the walking characteristics: The walking velocity, stride length, step frequency, pedestrian weight and the dynamic load amplification can be considered. For this purpose, it is obvious that although the stochastic approach is more efficient, more assumptions are required to be made. In their study, Pedersen and Frier investigated the effect of stochastic approach on vertical footbridge response to a single person loading. The results demonstrated that the bridge accelerations are not sensitive in case the walking parameters account as random variables. However, another two factors; the lateral response and the multi-person traffic have to be addressed as well.

In addition, Ingólfsson and Georgakis (2011) have addressed the issue of stochastic load modeling. They used the experimentally obtained forces (Ingólfsson et al., 2011) to define the total pedestrian-induced lateral force, $F(t)$, as an equivalent static force plus the additional equivalent damping and inertia forces, respectively. In contrast to the single person stochastic investigation of Pedersen and Frier, Ingólfsson and Georgakis showed that the modal response of a footbridge subjected to a pedestrian group is sensitive to the selection of the pacing rate distribution.

As it was noticed before, the complexity of the pedestrian's behavior during the use can hardly be evaluated. It is worth to mention that many elaborated studies (Živanović et al., 2005; Racic et al., 2009; Ingólfsson et al., 2011), have failed to indetify a commonly accepted human-structure interaction model, while some mathematical models have not yet been interconnected with the experimental observations (Ingólfsson et al., 2012). However, several characteristics can be identified by observing a typical shape of the lateral force generated by walking, such as the one in Fig. 1, as produced by Živanović et al. (2005).

From previous studies (Chao et al., 1983) the peak lateral forces have been measured approximately 4-5\% of the vertical weight, while evaluated the first five dynamic load factors were evaluated in the range 1.0$4.2 \%$ of the body weight (Bachmann and Ammann, 1987), which were verified lately by Ricciardelli and Pizzimenti (2007) through a stochastic approach- with $95 \%$ non-exceedance variability. 


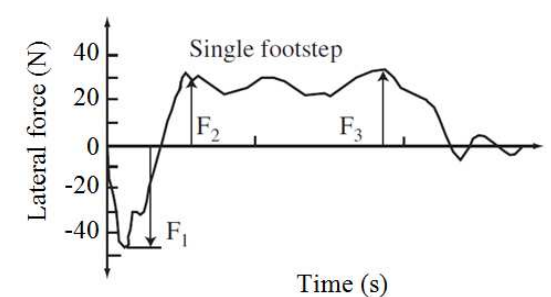

(a)

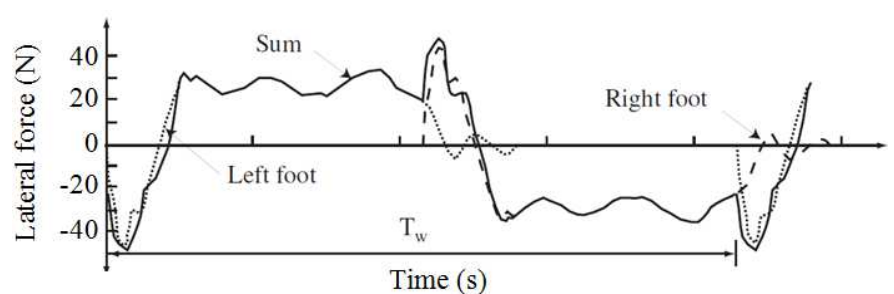

(b)

Fig. 1. Typical shape of lateral force by walking (a) a single footstep and (b) a series of footsteps (Živanović et al., 2005)

To an extent for several representative human activities such as walking, running, jumping, dancing, hand clapping and lateral body swaying, Bachmann (1992) and other researchers defined the typical frequency ranges after statistical elaboration as well as evaluated the dynamic load factors for the considered harmonics.

Various load models have been proposed to date, the most important of which are presented below. It is worth to note that it is widely accepted (and experimentally proved) that the pedestrians' distribution across the footbridge should be described as a periodic function of time and position. Equation 1 describes the motion of the structure; $u$ represents the modal displacement, $u^{\prime}$ the modal velocity and $u^{\prime \prime}$ the modal acceleration of the girder and $M, C$ and $K$ correspond to the modal mass, the modal damping coefficient and the modal stiffness, respectively. The external dynamic force is indicated by the right-hand side of Equation 1, $F_{p}(t)$ and the most conventional way to be expressed is obtained through a Fourier series, as shown in Equation 2:

$$
\begin{aligned}
& M u^{\prime \prime}(t)+C u^{\prime}(t)+K u(t)=F_{p}(t) \\
& F_{p}(t)=\sum_{i=1}^{n} G_{i} \sin \left(2 \pi i f_{i} t-\phi_{i}\right)
\end{aligned}
$$

where, $G_{i}$ and $\varphi_{i}$ denote the load amplitude and phase for the $\mathrm{i}^{\text {th }}$ mode.

In this way, the vibration induced by pedestrians can be modeled using: (a) A Single Degree Of Freedom (SDOF) method, (b) a Finite Element Method (FEM), (c) a response spectrum method, or (d) probabilistic procedures (e.g., Monte Carlo simulation). Although the first method is considered as the most easily used, an idealized pedestrian stream consisting of $N$ synchronized pedestrians is implemented, affecting the reliability of the results. For this reason, many researchers have addressed the issue by considering coefficients based on experimental results and/or stochastic procedures (e.g., Živanović et al., 2010), while considerable attention has been paid for the case of lateral loads.

Another issue which has attracted many researchers regards the phase of which modal characteristics (namely acceleration, velocity or displacement response of the structure) should be correlated with the resulting lateral force. The last observation was initiated by Arup's team hypothesis which demonstrated based on an experimental study for the case of Millennium footbridge, highlighting that the pedestrians' dynamic force is proportional to the velocity of the structure, as shown in Equation 3 and further indicating the moving pedestrians as negative dampers:

$F=k \cdot u^{\prime}(t)$

Dallard et al. (2001) further concluded that the lock-in effect can be associated with a limiting number of pedestrians, known as Arup's stability criterion Equation 4:

$N=\frac{8 \pi \xi M f}{k}$

where, $k$ denotes the proportional factor and $f$ the frequency of the lateral mode assuming a sinusoidal form Equation 5:

$\phi(x)=\sin \frac{2 \pi x}{L}$

Stability criteria have been reported by many researchers (e.g., Piccardo and Tubino, 2008), while several stability limits have been introduced in design guidelines as a function of the critical number of pedestrians or the critical acceleration (Sétra; BS 5400, 1978; Hivoss, 2008; etc.).

The load model described above was subsequently investigated by Nakamura, who proposed an improved non-linear dynamic model (Nakamura, 2004) Equation $6 \mathrm{a}$ and $\mathrm{b}$ :

$$
\begin{aligned}
& F_{p}(t)=k_{1} k_{2} H\left(u^{\prime}\right) G(f) M g \\
& H\left(x^{\prime}\right)=\frac{u^{\prime}}{k_{3}+\left|u^{\prime}\right|}
\end{aligned}
$$

where, $k_{1}$ and $k_{2}$ represent the proportion of the lateral force to the pedestrian's weight and the synchronized 
pedestrians percentage respectively. The non-linearity is implemented through the $H$ function which describes the synchronization nature (depending on the structure's velocity, $u^{\prime}$ ) and $G$ describes how pedestrians synchronize with the bridge natural frequency. The coefficient $k_{3}$ is established for the corresponding data measured from the T-bridge in Japan. In any case, the need for a non-deterministic approach is stressed through several studies (Nakamura and Kawasaki, 2009). Recently, Zhen et al. (2013) draw some interesting findings using the bifurcation theory, while highlighting the great non-linearity of lateral vibrations and concluding the need of new models evaluating the lateral forces, since the coefficients used in Dallard's and Nakamura's models may differ significantly for other case studies. In Fig. 2, the comparison of the aforementioned load models has arrived for the coefficients: $k=300 \mathrm{Ns} / \mathrm{m}$ (Dallard's model) and $k_{1}=0.04 ; k_{2}=0.2 ; k_{3}=0.01 \mathrm{~m} / \mathrm{s} ; M$ $=65 \mathrm{~kg}$ (Nakamura's model).

Pizzimenti and Ricciardelli (2005) distinguished two different types of loading mechanisms, the first one is corresponding to the walking and the vibration frequency, while the second one ("self-excited force") was subdivided into the in-phase and out-of-phase lateral force. The in-phase excitation implies negative mass (or positive stiffness) to the system, while the out-of-phase (greater than $90^{\circ}$ ) excitation corresponds to additional structural damping.

The latter study referred to the displacement phase correlation. Nevertheless, the new findings should be verified through more quantitative results. For this reason, an invaluable experimental campaign was conducted by Ingólfsson et al. (2011) adopting the moving surface framework of Pizzimenti and Ricciardelli (2005). The results indicated that, with a small exception at low frequencies (below 0.5 of the mean walking frequency, $\bar{f}_{w}$ ), pedestrians extract energy from the structure (negative damping), while the added stiffness is also observed for the dimensionless frequency ratio below $0.55-0.85$. Furthermore, the large variability in results is highlighting once again the need for a probabilistic approach.

Furthermore, researchers (Abe and Fujino, 1992; Barker, 2002; Hof et al., 2007; Macdonald, 2009; Carroll et al., 2011) have studied an inverted pendulum model, inspired by the field of biomechanics. As indicated in by Macdonald (2009), the lateral displacement and velocity of the center of pedestrian's mass prior to the foot placement are the most important control parameters, while the pedestrians can be well represented by added damping and mass, rather than by external forces. Also, the introduction of random (Gaussian) variations of the foot placement position and timing, revealed scatter results, with no significant difference on the corresponding mean values.

Interesting studies have been presented by Bocian et al. (2012; 2013), in an attempt to identify the susceptibility of the resulting bridge response arising from the Macdonald's inverted pendulum model, in terms of added modal damping and mass. Particularly, the equivalent added damping, $\Delta C$ and mass, $\Delta M$, are quantified for a wide range of bridge response frequency, taking into account variations of leg lengths and pedestrian walking frequency. Both the negative and positive effects of damping and mass are clearly noticed for specific bridge frequency ranges, while the instability limits are defined in terms of frequency ratios, $\omega_{b} / \omega_{n}$ and critical damping ratios, $\zeta$, for different pedestrian to bridge mass ratios, $\mu=m / M$.

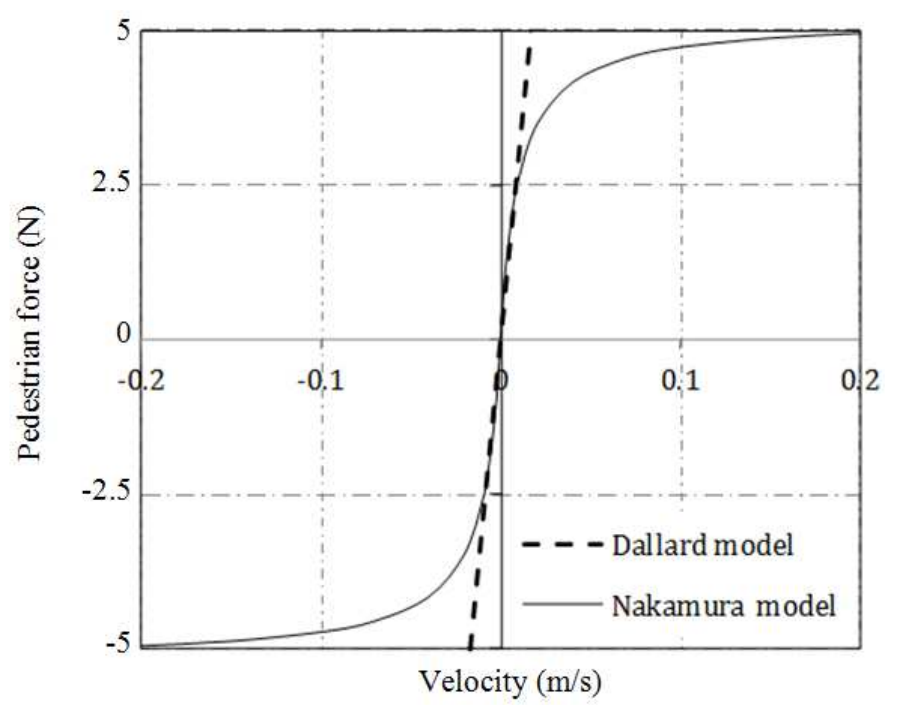

Fig. 2. Comparison of Dallard's and Nakamura's load models 
To an extent of the above findings, the critical number of pedestrians needed to produce synchronous lateral excitation may vary considerably depending on the particular crowd characteristics. On the other hand, as mentioned by Dallard et al. (2001), the analysis or experimental tests are not always close to reality, since people often exhibit 'meandering' patterns in their walking.

\section{Code Provisions}

In this section, a brief summary of the design procedures is presented, evaluating the footbridge dynamic response under pedestrian loads. In general, the loading model based on a single person excitation was implemented by Matsumoto et al. (1978), while all the specifications are time-domain modeled.

\section{BS 5400}

The BS 5400 Standard is one of the earliest developed codes of practice addressing vibrations on footbridges. In the last edition, deflection criteria are implemented, for the cases of natural frequencies below 5 and $1.5 \mathrm{~Hz}$, for vertical and horizontal directions, respectively. For more complex structures, the maximum vertical acceleration should be calculated by imposing a movable point load, $F$ Equation 7:

$$
F(t)=180 \sin \left(2 \pi f_{0} t\right)
$$

where, $f_{0}$ represents the fundamental frequency of the footbridge.

\section{Eurocode 5-Part 2}

Although Eurocode 5 concerns timber bridges, the response model could be used for any material. Nevertheless, it regards simply supported beams or truss systems, while the walking frequency is not taken into account for the dynamic response. In addition, although the serviceability check is exempt in case the fundamental frequency of the bridge is greater than $5 \mathrm{~Hz}$ for vertical vibrations and $2.5 \mathrm{~Hz}$ for lateral and torsional vibrations, comfort criteria are defined in terms of accelerations without frequency dependence (Eurocode 0, Annex A2). The last observations make Eurocode restricted for wide usage.

Particularly for the horizontal vibrations, the horizontal acceleration for several pedestrians crossing the bridge, $a_{h o r, n}$, are calculated as follows Equation $8 \mathrm{a}$ and $\mathrm{b}$ :

$$
a_{h o r, 1}=\frac{50}{M \zeta}, \text { for } 0.5 \mathrm{~Hz} \leq f n \leq 2.5 \mathrm{~Hz}
$$

$$
a_{h o r, n}=0.18 a_{h o r, 1} n k_{h o r}
$$

where, $n$ (which is the number of pedestrians) should be taken as 13 or $0.6 A$ (i.e., $60 \%$ of the bridge deck area) and $k_{h o r}$ is the coefficient according to the natural frequency of the structure, $f_{n}$. The latter factor is illustrated for both vertical and horizontal directions in Fig. 3.

\section{ISO 10137}

According to Annex A of ISO 10137 (2007), in contrast to the Eurocode, the dynamic force $F(t)$ produced by a person walking on a footbridge can be expressed as a Fourier series for each direction, as demonstrated in Equation 9:

$$
F_{1}(t)=W\left(1+\sum_{n=1}^{k} a_{n} \sin \left(2 \pi n f_{p} t+\varphi_{n}\right)\right)
$$

where, $W$ represents the pedestrian's weight, $a_{n}$ the dynamic load factor (or the ratio of the lateral force to the pedestrian's weight) and $f_{p}$ the pacing frequency. The dynamic factor for the first mode is expressed proportional to the walking frequency, while for the next 5 harmonics is defined as $a_{2}=0.1, a_{3}=a_{4}=a_{5}=0.06$. However, through this approach an over-conservative assumption is introduced by the fact that all users synchronize with the structure (Ingólfsson et al., 2007).

\section{Sétra}

Using Sétra guidelines, footbridge categorization is implemented taking into account both the traffic and the comfort levels. In case the studied structure's resonance level is negligible, the footbridge is judged sufficient and no further calculation is required.

Otherwise, the direction of the dynamic load corresponds to the sign of the mode shape, while its amplitude is defined as Equation 10a to c:

$$
\begin{aligned}
& f_{N}(t)=N_{e q} \frac{F_{0}}{A} \psi \cos \left(2 \pi f_{n} t\right) \\
& N_{e q}=10.8 \sqrt{N \xi}, \text { for sparse or dense crowd } \\
& N_{e q}=1.85 \sqrt{N}, \text { for very dense crowd }
\end{aligned}
$$

where, $F_{0}, A$ and $N_{e q}$ represent the load amplitude of a single pedestrian, the bridge deck area and the number of people (separately for two types of crowd), respectively. $f_{n}$ is the natural frequency and $\psi$ denotes the reduction of load for excitations away from the average pacing ratio. After the maximum acceleration is established, the comfort criteria are implemented to check whether the structure exhibits within the acceleration limits or not. 


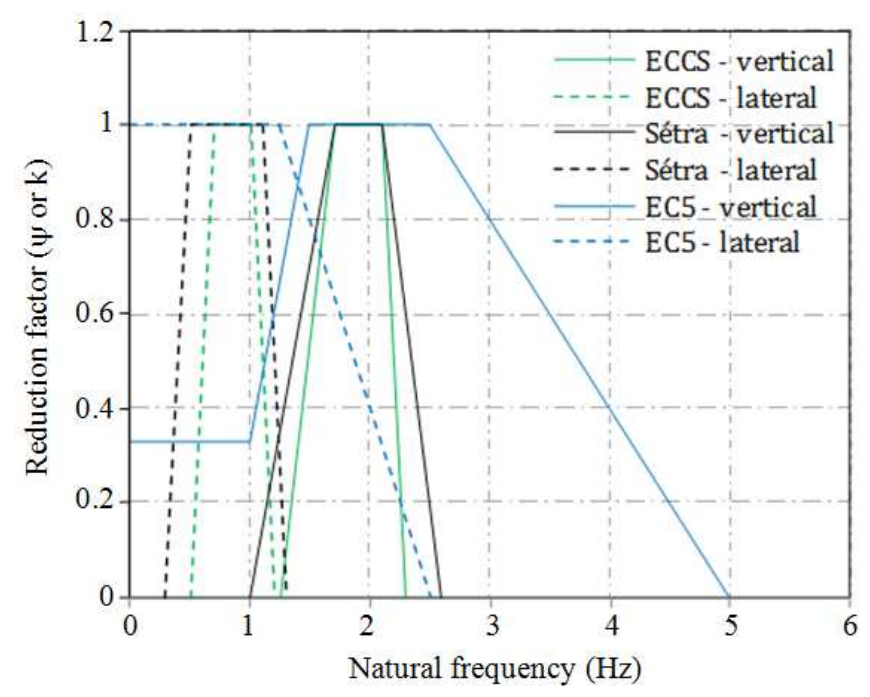

Fig. 3. Comparison of reduction factors as a function of natural frequency

The criterion of the acceleration limit should be considered, as expected, more relevant than the critical number of pedestrians, since through critical acceleration the concept of the problem is more realistically simulated, while the stability criteria can be effectively applied. Besides, as it is mentioned in the current guide "acceleration actually corresponds to what the pedestrians feel whereas a critical number of pedestrians depends on the way the pedestrians are organized and positioned on the footbridge". The methodology of Sétra Guidelines was presented recently by Saouridis and Remy (2014), along with the implementation on two case studies.

\section{$J R C / E C C S$}

JRC/ECCS specifications are based on recent projects (Butz, 2007; Hivoss, 2008), while the relation with the French Sétra Guidelines is apparent. Some important modifications are highlighted herein, such as wider critical ranges are specified regarding the natural frequencies, for both vertical and longitudinal directions. In particular, the upper limit of the vertical vibrations is expanded to $4.6 \mathrm{~Hz}$ in order to take into account the second harmonic. In addition, the comfort classes are presented as defined in Sétra guidelines, while traffic classes.

Both deterministic and probabilistic approaches have been demonstrated for the response to distributed harmonic loads, while SDOF method and response spectra method are also presented in these guidelines. Specific information is attached for the dynamic properties' evaluation of a footbridge, assisted by testing procedures. Finally, numerous case studies for which damping systems have been implemented are presented in tabular form.

The reduction factors for the dynamic forces produced by pedestrians, are presented according to three European Guidelines (JRC/ECCS, Sétra and
EC5) for both vertical and lateral directions (Fig. 3). Thus, the risk frequencies' comparison for each specification can be schematically observed. For a more comprehensive compilation of risk frequencies from various published guidelines the reader is referenced to Table 1.2 of Sétra (2006). The overconservation of the Eurocode is also apparent.

\section{Case Studies}

The most valuable observations about the dynamic behavior of footbridges under pedestrian loads have been recorded through studying existing structures. For this reason, case studies for which excessive instability phenomena has occurred, are presented in this study.

London Millennium Bridge (Fig. 4) is rather a conventional bridge. The structural system stiffness is almost derived by the cable tension $(80 \%$ of the total stiffness), since the deck is supported on the cables (Fitzpatrick et al., 2001). Dallard et al. (2001) highlighted the torsion effects on both vertical and horizontal response. The fact that a large mass distribution is obtained through the cables, results in the torsion modes having relatively high modal mass. However, although the torsional modes were generally less excitable than the vertical ones, the maximum lateral acceleration recorded on the bridge was over $0.2 \mathrm{~g}$ (contrary to $0.02 \mathrm{~g}$ predicted during the analysis).

Nevertheless, it was resulted that synchronous lateral excitation is not attributed to the innovative design of the London Millennium Bridge (Dallard et al., 2001). According to the literature, a significant number of cases are found to be sensitive to the same phenomenon. For comparative reasons, examples of several footbridge types are reviewed in Table 1, where one can observe the main features, namely the first mode frequency and type, along 
with the corresponding length and type of each footbridge. Many of the cases below regard footbridges where damping systems are implemented. In addition, two of the most wellknown footbridges, the Solferino footbridge (Paris) and the M-bridge (Japan), are shown in Fig. 5 and 6, respectively.

\section{Vibration Upgrading}

One way for reducing the dynamic effects on an existing footbridge is, clearly, the reduction of accelerations. However, through the vibration upgrading process, one should also consider the modification of the natural frequencies. For that reason, several highlights according to (Sétra, 2006) are synopsized herein.

Ultimately, it should be noted that extensive structural modifications (which imply time and cost effective solutions) are needed for the re-arrangement of the footbridge's stiffness. In case the first mode is within the range of risk, one should take into account that decreasing it below the range of risk, the second one is retained above that critical range. Otherwise, increasing the flexibility of the structure leads to higher deflections.

Table 1. Considered case studies of footbridges

\begin{tabular}{|c|c|c|c|c|c|}
\hline Reference & Bridge type & $\mathrm{Hz}^{\mathrm{a}}$ & Length $(\mathrm{m})$ & Mode type & Bridge \\
\hline \multirow[t]{8}{*}{$\overline{\text { Sétra (2006) }}$} & Warren-type lateral beams & 1.95 & $49.7+49.7$ & vertical bending & Cavaillon footbridge \\
\hline & steel box-girder & 1.97 & $54+50+64$ & vertical bending central bay & Stade de France footbridge \\
\hline & ribbed slab & 1.65 & $22+22+44$ & vertical bending & Noisy-le-Grand footbridge \\
\hline & bow-string arch & 2.54 & 55 & vertical bending & Montigny-les-Cormeilles \\
\hline & suspended construction & 1.1 & 60.0 & lateral bending of deck & Footbridge over the Aisne at Soissons \\
\hline & steel arch & 0.71 & 106 & lateral swing & Solferino Bridge \\
\hline & cable-stayed construction & 1.38 & $68+36+42+42$ & lateral bending of deck & Pas-du-lac footbridge at St Quentin \\
\hline & mixed construction beam & 2.15 & 23 & vertical bending & Mon-Saint-Martin footbridge \\
\hline Nakamura and Fujino (2002) & cable-stayed/continuous box girder & 0.93 & $45+134$ & lateral & T-bridge, Japan \\
\hline Breukleman et al. (2002) & steel beam girder & $1.7-2.2$ & - & vertical & Bellagio to Bally's footbridge, Las Vegas \\
\hline Hatanaka and Kwon (2002) & steel box girder & 1.84 & 47.4 & vertical & Simply supported footbridge \\
\hline Collete (2002) & steel beams & 4.3 & 28 & vertical & Footbridge on large atrium \\
\hline \multirow[t]{4}{*}{ Caetano et al. (2007) } & steel box girder & 0.8 & - & vertical & Mjomnesundet bridge, Norway \\
\hline & steel cable-stayed/steel arch & 1.9 & 209 & vertical & Schwedter Straße bridge, Berlin \\
\hline & hinged steel arch/orthotropic deck & 5.6 & 33.8 & vertical & Britzer Damm footbridge, Berlin \\
\hline & shallow arch/girder & 0.85 & 110 & lateral/vertical & Pedro 3 Ines Bridge, Coimbra \\
\hline Seiler et al. (2002) & cable-stayed construction & $1.0-3.0$ & 117.5 & vertical & Forchheim Bridge, Germany \\
\hline \multirow[t]{2}{*}{ JRC/ECCS (2009) } & suspension bridge & 0.24 & $38+103+38$ & horizontal & Weser River Footbridge, Minden \\
\hline & steel arch & 0.63 & $15+90+15$ & lateral & Guarda Footbridge, Portugal \\
\hline Dallard et al. (2001) & suspension tension-ribbon & 0.48 & $108+144+80$ & lateral & London Millennium footbridge \\
\hline Nakamura et al. (2006) & suspension bridge & 0.5 & $60+320+60$ & - & Maple Valley Great Suspension Bridge (M-bridge) \\
\hline \multirow{3}{*}{ Pantak et al. (2012) } & suspension bridge & 1.44 & 51.2 & - & Węgierska Górka, Poland \\
\hline & steel truss arch & 2.14 & 45 & - & Łapanów, Poland \\
\hline & suspension bridge & 1.4 & 102 & - & Nový Dvůr near Brno, Czech Republic \\
\hline \multirow[t]{8}{*}{ Van Nimmen et al. (2014) } & steel U-shaped cross section & $1.71(2.03)$ & 96 & - & Eeklo footbridge \\
\hline & steel tied-arch & $0.71(0.74)$ & 107 & - & Wetteren footbridge \\
\hline & steel cable-stayed with a 3D truss & $2.97(2.93)$ & 58.5 & - & Ninove footbridge \\
\hline & steel hammock with concrete deck & $1.55(1.67)$ & 106 & - & Knokke footbridge \\
\hline & steel structure & $3.06(2.92)$ & 23 & - & Leuven footbridge \\
\hline & steel arch bridge & $2.85(3.04)$ & 57 & - & Anderlecht footbridge \\
\hline & steel L-shaped cross section & $3.75(3.7)$ & 31 & - & Mechelen footbridge \\
\hline & steel U-shaped cross section & $1.64(1.86)$ & 57 & - & Brugge footbridge \\
\hline Black and Webster (2006) & semi-tied bowstring arch & $2.07(2.03)$ & 77.0 & - & Jane Coston Cycle bridge \\
\hline
\end{tabular}

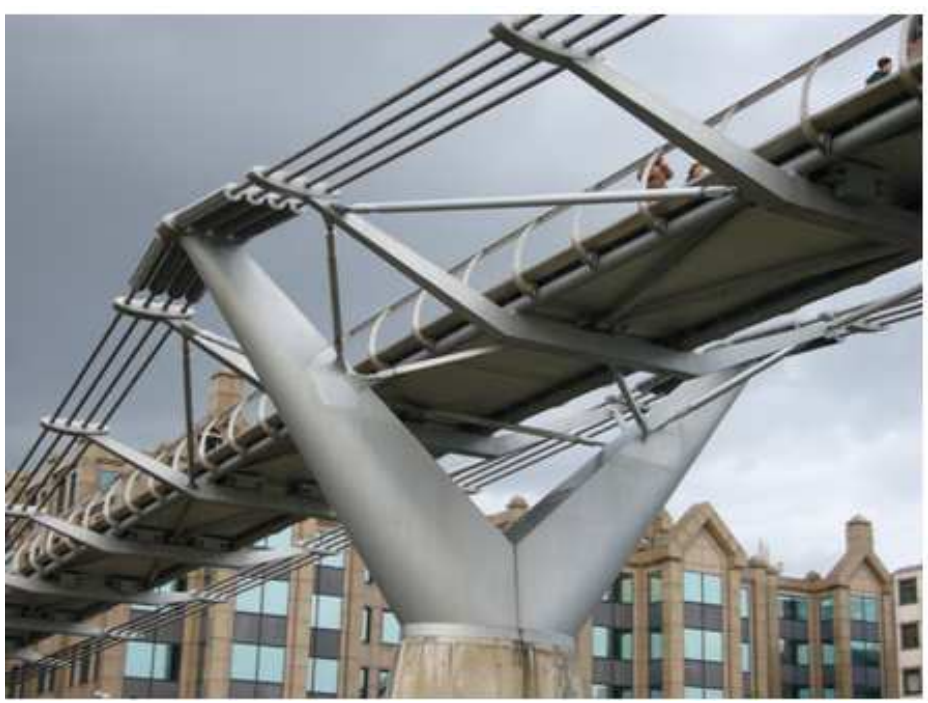

Fig. 4. View of the London Millennium Bridge (Brownjohn et al., 2008) 


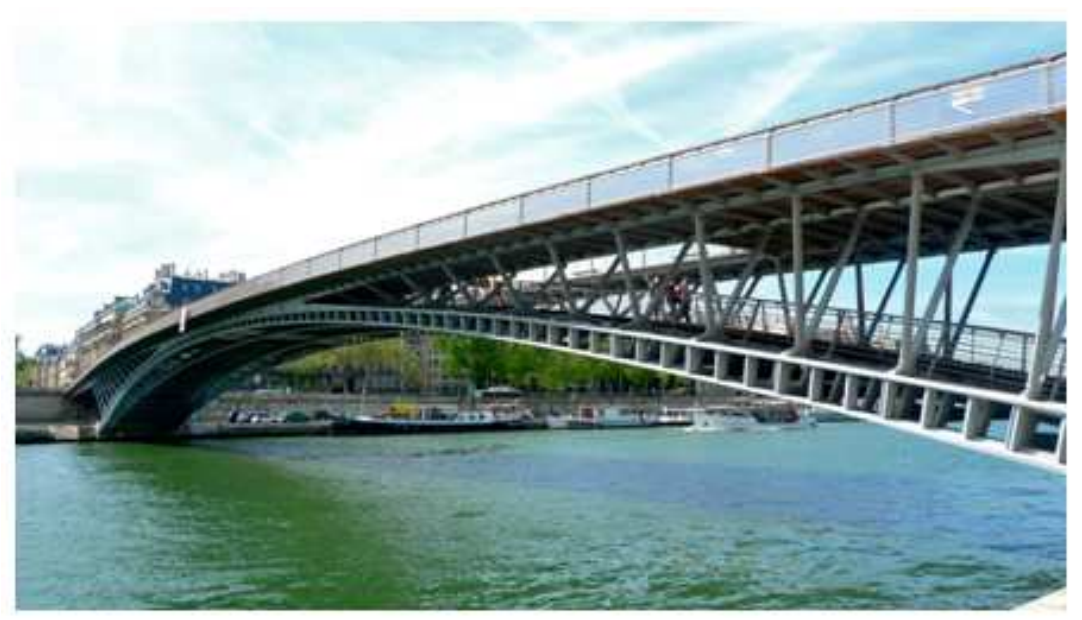

Fig. 5. View of the Solferino footbridge in Paris

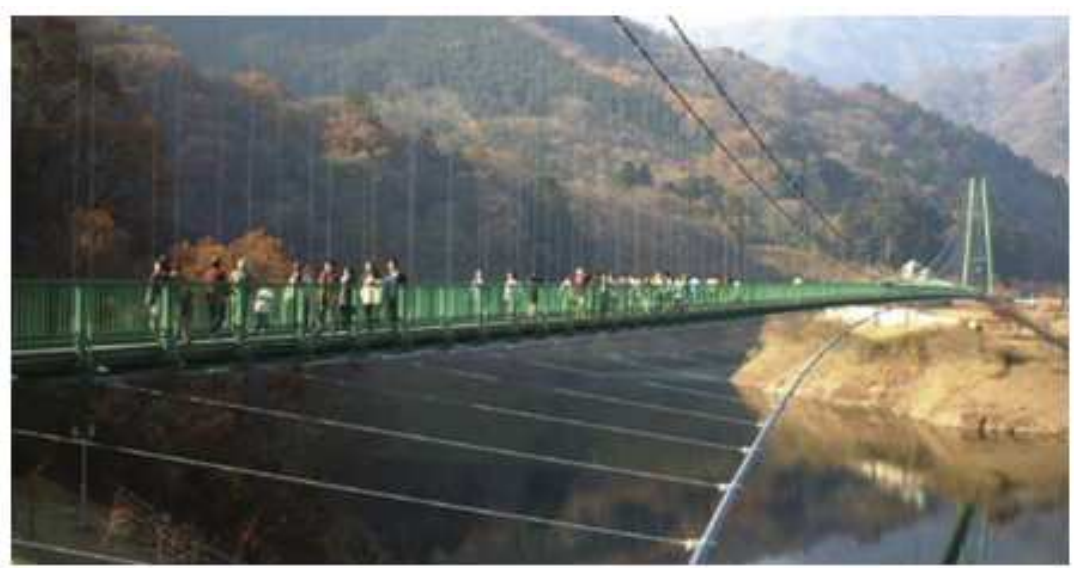

Fig. 6. View of the Nasu Shiobara footbridge in Japan (M-bridge)

In particular, the most efficient way of upgrading the natural frequencies is regarded the increase of the stiffness by reducing (or without increasing) the mass of the system. This could be achieved by improving the geometrical or material properties (e.g., modulus of elasticity, strength, etc.). In other case, the simultaneous increase of both the stiffness and the mass reduces the overall effect. Nevertheless, although the increase of the mass leads to the reduction of the natural frequency (which is found insignificant), it also implies reduction of the accumulated accelerations (inversely proportional).

An alternative solution of major importance is regarded the installation of damping systems. Three major damping systems are found in the literature: Tuned mass (or liquid) dampers, viscous (and friction) dampers and the active control.

Tuned Mass Dampers (TMDs) are the most popular, as they are easily-installed and very effective for damping out excessive vibrations. However, the damping ratio has to be maintained for the TMD lifetime. In addition, the proper installation position should be chosen to allow easy maintenance and inspection without the need for special trafficmanagement measures. A representative example of a TMD is schematically illustrated in Fig. 7 (Black and Webster, 2006).

On the other hand, viscous and friction dampers are energy-dissipating, for the operation of which two points of the structure should be connected. The active control systems use computer-controlled powered components which induce the certain forces to cancel out the dynamic actions. The successful application of fluid viscous dampers to earthquake resistant design has also been extensively discussed many years ago by Constantinou (1994). In addition, semi-active TMDs are developed by Occhiuzzi et al. (2008) by adjusting their dynamic parameters based on a magnetorheological fluid-control strategy by varying the intensity of the magnetic field, while different combinations of viscous 
and friction types of behavior can be achieved. The effectiveness of semi-active TMDs is also presented in Demetriou et al. (2015).

London Millennium footbridge and Toda footbridge in Japan, are regarded two of the most well-known cases of dampers installation. Dallard et al. (2001) elaborately describe the design process for the vibration upgrading of Millennium footbridge, where 37 fluid viscous dampers were installed to cancel out the horizontal vibrations as well as tuned mass dampers for the vertical vibrations (some of these can be seen in Fig. 4). The sufficient use of the first ones were ensured by connecting the dampers (where possible) to fixed points (piers and ground). To provide horizontal damping for the Toda footbridge, Tuned Liquid
Dampers (TLDs) corresponding to $0.7 \%$ of the total mass were used (Nakamura and Fujino, 2002).

The optimum frequency and damping amplitudes are expressed through Equation 11a and b (Den Hartog, 1940):

$$
\begin{aligned}
& f_{\text {opt }}=\frac{f_{H}}{1+m_{T} / m_{H}} \\
& \zeta_{\text {opt }}=\sqrt{\frac{3 m_{T} / m_{H}}{8\left(1+m_{T} / m_{H}\right)^{3}}}
\end{aligned}
$$

where, $m_{T}$ and $m_{H}$ denote the damper mass and the main system mass, respectively.

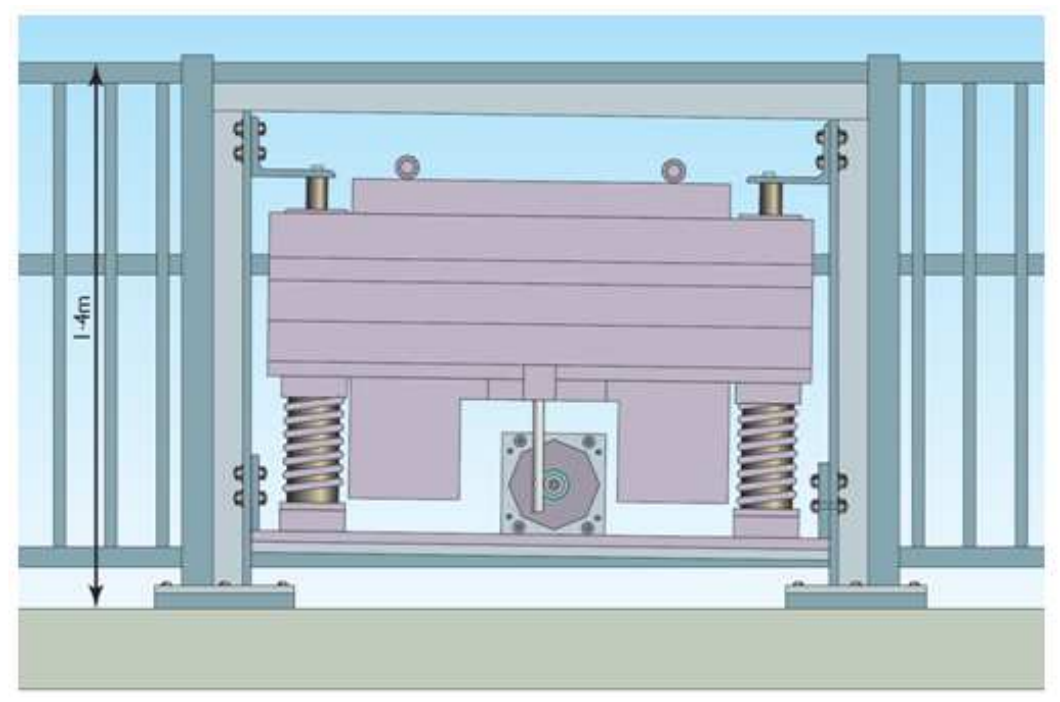

Fig. 7. Presentation of TMD installed in Jane Coston Cycle Bridge (Black and Webster, 2006)

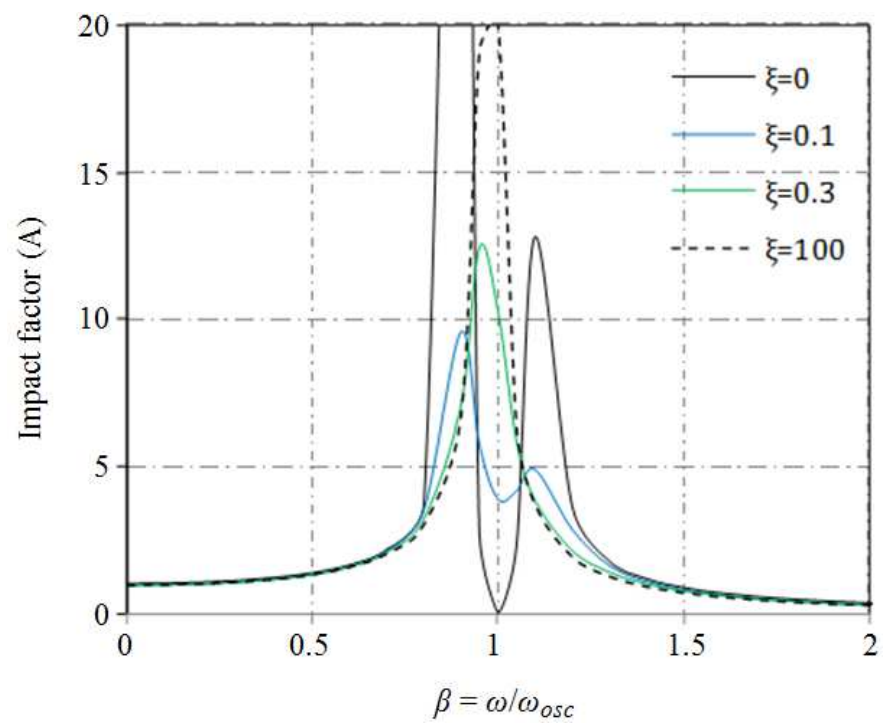

Fig. 8. Effect of a tuned mass damper according to (Den Hartog, 1940), for $\mu=0.05, \alpha=1$ and several damping ratios 
In general, the proper ratio $m_{T} / m_{H}$ is found to lie between $2-5 \%$, while the damping coefficient has been observed to reach great values $(20 \%)$, along with significant reduction of the produced accelerations (up to 20 times), according to the literature (Dallard et al., 2001).

In Fig. 8 (Sétra, Appendix 3), the vertical axis represents the impact factor $A$, defined as the ratio of the maximum dynamic to the static displacement and depends on the parameters: The mass ratio $\mu=m / M$, the frequency ratios $\alpha=\omega_{\text {ada }} / \omega_{\text {osc }}$ and $\beta=\omega / \omega_{\text {osc }}$ and the damping ratio of the damper, $\xi_{\text {ada }}$. Particularly for great damping values of the TMD, the two masses are virtually fused, forming a single oscillator of mass equal to $m+M$. The two humps generated are more than obvious for the two-degrees-of-freedom system, while the optimum damping coefficient is obtained through Equation $11 \mathrm{~b}$ approximately 0.13 . For more information about the effectiveness and the applicability of tuned absorbers the reader is referenced to Bachmann and Weber (1995), Bachmann (1992) and Meinhardt et al. (2008).

\section{Conclusion}

This work consists a thoroughly review of the dynamic response of footbridges under pedestrian loads. Initially, some qualitative information is given for the introduction to the problem. Regarding the correlation between the forces generated by the pedestrians and the movements of the bridge, safe conclusions can be drawn only by considering the produced accelerations (separately for vertical and horizontal directions). In particular, regarding low levels of accelerations compared with the corresponding acceleration limit, the recorded forces are considered rather random. In case one follows a conservative approach, a number of assumptions should be considered such as the increased crowd density (at whole or local areas), the correlation between pedestrians, the absence of passive human (and generally the neglect of the pedestrians' participation to the overall structural damping) and the allowance of random component.

Furthermore, the main deterministic time-domain load models are presented, while the need for probabilistic methods is also highlighted. This is regarded essential to obtain the approach of the design guidelines, which are illustrated subsequently. This study includes briefly the principles of BS 5400, EC5, ISO, Sétra and JRC/ECCS guidelines and specifications.

The design of a footbridge should accommodate the provision of dampers, in order to constrain large dynamic effects. Vibration testing after the bridge installation may be regarded as an obligatory provision (at least for identical case studies) adopted by the national codes, in order to monitor whether specific vibrations (or comfort and stability) criteria have been met. Otherwise, vibration upgrading measures will have to be implemented for the safe use of the footbridge. For the latter case, conventional cases of damping systems are exemplified and examples of implementations are presented.

\section{Author's Contributions}

All authors equally contributed in this work.

\section{Ethics}

No ethical issues are encountered by the authors.

\section{References}

Abe, M. and Y. Fujino, 1992. A simulation on pedestrianinduced lateral vibration of a bridge using a two-legs human model. J. Struct. Eng., 441: 199-202.

Bachmann, H. and W. Ammann, 1987. Vibrations in Structures: Induced by Man and Machines. 1st Edn., IABSE, Zürich, pp: 176.

Bachmann, H., 1992. Vibration upgrading of gymnasia, dance halls and footbridges. IABSE Struct. Eng. Int., 2: 118-124. DOI: $10.2749 / 101686692780615978$

Bachmann, H. and B. Weber, 1995. Tuned vibration absorbers for "lively" structures. IABSE Struct. Eng. Int., 1: 31-36. DOI: 10.2749/101686695780601457

Barker, C., 2002. Some observations on the nature of the mechanism that drives the self-excited lateral response of footbridges. Proceedings, of the Design and Dynamic Behaviour of Footbridges, Nov. 20-22, Footbridge, Paris.

Black, M. and G. Webster, 2006. Jane Coston Cycle bridge: A model for managing vibration. Proc. ICE Civil Eng., 159: 120-125. 9

Breukleman, B., S. Gamble, J. Kottenlenberg and T. Haskett, 2002. Footbridge damping systems: A case study. Proceedings of the Design and Dynamic Behaviour of Footbridges, Nov. 20-22, Footbridge, Paris, pp: 222-223.

Brownjohn, J., S. Živanović and A. Pavić, 2008. Crowd dynamic loading on footbridges. Proceedings of the 3rd International Conference, Jul. 2-4, Footbridge, Porto.

BS 5400, 1978. Part 2, Appendix C: Permissible vibrations for footbridges and cycle track bridges. British Standards Association, London, UK.

Butz, C., F. Magalhaes, A. Cunha, E. Caetano and A. Goldack, 2005. Experimental characterization of the dynamic behaviour of lively footbridges. Proceedings of the 2nd International Conference, Dec. 6-8, Footbridge, Venice. 
Butz, C., 2007. Advanced load models for synchronous pedestrian excitation and optimised design guidelines for steel foot bridges (SYNPEX). Project RFS-CR-03019, Final Report.

Caetano, E., A. Cunha and C. Moutinho, 2007. Implementation of passive devices for vibration control at Coimbra footbridge. EVACES, Porto.

Carroll, S.P., J.S. Owen and M.F.M. Hussein, 2011. Crowd-bridge interaction by combining biomechanical and discrete element models. Proceedings of the 8th International Conference on Structural Dynamics, (CSD’11), Leuven.

Bocian, M., J.H.G. Macdonald and J.F. Burn, 2012. Biomechanically inspired modelling of pedestrian-induced forces on laterally oscillating structures. J. Sound Vibrat., 331: 3914-3929. DOI: $10.1016 /$ j.jsv.2012.03.023

Bocian, Mateusz, John H.G. Macdonald and Jeremy F. Burn, 2013. Biomechanically inspired modeling of pedestrian-induced vertical self-excited forces. ASCE J. Bridge Eng., 18: 1336-1346. DOI: $10.1061 /(A S C E) B E .1943-5592.0000490$

Chao, E.Y., R.K. Laughman, E. Schneider and R.N. Stauffer, 1983. Normative data of knee joint motion and ground reaction forces in adult level walking. J. Biomechan., 16: 219-233. DOI: $10.1016 / 0021-9290(83) 90129-\mathrm{X}$

Collete, F.S., 2002. Tuned mass dampers for a suspended structure of footbridges and meeting boxes. Proceedings of the Design and Dynamic Behaviour of Footbridges, Nov. 20-22, Footbridge, Paris, pp: 208-209.

Constantinou, M., 1994. Application of fluid viscous dampers to earthquake resistant design. Research Accomplishments, Buffalo: National Center for Earthquake Engineering Research.

Dallard P., A.J. Fitzpatrick, A. Flint, S. Le Bourva, A. Low and R.M. Ridsdill Smith et al., 2001. The London Millennium footbridge. Struct. Engineer, 79: 17-33.

De Donno, A., D. Powell and A. Low, 2005. Design of damping systems for footbridges, Conceptual framework. Proceedings of the 2nd International Conference, Dec. 6-8, Footbridge, Venice.

Den Hartog, J.P., 1940. Mechanical Vibrations. 1st Edn., McGraw-Hill, New York.

Demetriou, D., K.D. Tsavdaridis and N. Nikitas, 2015. Tuning and shaping semi-active tuned mass dampers for use on high-rise wind excited structures. Proceedings of the 17th Young Researchers' Conference, April 14, ISE, pp: 36-37.

Fitzpatrick, A.J., P. Dallard, S. Le Bourva, A. Low and R.M. Ridsdill Smith et al., 2001. Linking London: The millennium bridge. The Royal Academy of Engineering, London.
Hatanaka, A. and Y. Kwon, 2002. Retrofit of footbridge for pedestrian induced vibration using compact tuned mass damper. Proceedings of the Design and Dynamic Behaviour of Footbridges, Nov. 20-22, Footbridge, Paris, pp: 210-211.

HIVOSS, 2008. Design of footbridges guideline. Human induced vibrations of steel structures. RFS2-CT2007-00033.

Hof, A.L., R.M. van Bockel, T. Shoppen and K. Postema, 2007. Control of lateral balance in walking: Experimental findings in normal subjects and above-knee amputees. Gait Posture, 25: 250-258. DOI: 10.1016/j.gaitpost.2006.04.013

Ingólfsson, E.T., C. Georgakis, J. Jönsson and F. Ricciardelli, 2007. Vertical footbridge vibrations: Towards an improved codifiable response evaluation. Proceedings of the 3rd International Conference on Structural Engineering, Mechanics and Computation, Cape Town, South Africa.

Ingólfsson, E.T., C.T. Georgakis, F. Ricciardelli and J. Jönsson, 2011. Experimental identification of pedestrian-induced lateral forces on footbridges. J. Sound Vibrat., 330: 1265-1284.

DOI: $10.1016 /$ j.jsv.2010.09.034

Ingólfsson, E.T. and C.T. Georgakis, 2011. A stochastic load model for pedestrian-induced lateral forces on footbridges. Eng. Struct., 33: 3454-3470. DOI: 10.1016/j.engstruct.2011.07.009

Ingólfsson, E.T., C.T. Georgakis and J. Jönsson, 2012. Pedestrian-induced lateral vibrations of footbridges: A literature review. Eng. Struct., 45: 21-52. DOI: 10.1016/j.engstruct.2012.05.038

ISO 10137, 2007. Bases for design of structuresServiceability of buildings and walkways against vibration. ISO 10137: 2007, International Organization for Standardization.

JRC/ECCS, 2009. Design of lightweight footbridges for human induced vibrations. JRC Scientific and Technical Reports.

Macdonald, J.H.G., 2009. Lateral excitation of bridges by balancing pedestrians. Proceedings: Royal Society A, 465: 1055-1073.

Matsumoto, Y., T. Nishioka, H. Shiojiri and K. Matsuzaki, 1978. Dynamic design of footbridges. Proc IABSE, 2: 1-15.

Meinhardt, C., O. Dressen and F. Dalmer, 2008. Increase of the structural damping due to the application of tuned mass dampers TMD subject to the footbridge construction. Proceedings of the 3rd International Conference, Jul. 2-4, Footbridge, Porto.

Nakamura, S., 2004. Model for lateral excitation of footbridges by synchronous walking. ASCE J. Struct. Eng., 130: 32-37. DOI: 10.1061/(ASCE)0733-9445(2004)130:1(32) 
Nakamura, S. and Y. Fujino. 2002. Lateral vibration on a pedestrian cable-stayed bridge. IABSE Struct. Eng. Int., 12: 295-300. DOI: $10.2749 / 101686602777965162$

Nakamura, S. and T. Kawasaki, 2009. A method for predicting the lateral girder response of footbridges induced by pedestrians. J. Construct. Steel Res., 65: 1705-1711. DOI: 10.1016/j.jcsr.2009.03.003

Nakamura, T., M. Small and Y. Hirata, 2006. Testing for nonlinearity in irregular fluctuations with longterm trends. Phys. Rev. E, 74: 026205-026205. DOI: 10.1103/PhysRevE.74.026205

Occhiuzzi, A., M. Spizzuoco and F. Ricciardelli, 2008. Loading models and response control of footbridges excited by running pedestrians. Struct. Control Health Monitor., 15: 349-368. DOI: 10.1002/stc.248

Pantak, M., B. Jarek and W. Średniawa, 2012. Application of EN 1990/A1 vibration serviceability limit state requirements for steel footbridges. Steel Struct. Bridges, 40: 345-350. DOI: $10.1016 /$ j.proeng.2012.07.106

Piccardo, G. and F. Tubino, 2008. Parametric resonance of flexible footbridges under crowdinduced lateral excitation. J. Sound Vibrat., 311: 353-371. DOI: 10.1016/j.jsv.2007.09.008

Pedersen, L. and C. Frier, 2013. Sensitivity of footbridge response to load modeling. Proceedings of the Conference of the Society for Experimental Mechanics Series 26, Topics in Dynamics of Civil Structures, (DCS' 13), pp: 51-58.

Pedersen, L., 2013. Some implications of humanstructure interaction. Proceedings of the Conference of the Society for Experimental Mechanics Series 39, Topics in Dynamics of Civil Structures, (DCS' 13), pp: 155-161.

Pizzimenti, A. and F. Ricciardelli, 2005. Experimental evaluation of the dynamic lateral loading of footbridges by walking pedestrians. Proceedings of the 6th European Conference on Structural Dynamics, (CSD’ 05), Paris.

Racic, V., A. Pavic and J.M.W. Brownjohn, 2009. Experimental identification and analytical modelling of human walking forces: Literature review. J. Sound Vibrat., 326: 1-49.

DOI: $10.1016 /$ j.jsv.2009.04.020

Ricciardelli, F. and D. Pizzimenti, 2007. Lateral walking-induced forces on footbridges. ASCE J. Bridge Eng., 12: 677-688.

DOI: 10.1061/(ASCE)1084-0702(2007)12:6(677)

Saouridis, C. and B. Rémy, 2014. Footbridges: Vibrato, ma non troppo. Proceedings of the 8th National Hellenic Conference of Steel Structures, Oct. 2-4, Greece.
Seiler, C., O. Fischer and P. Huber, 2002. Semi-active MR dampers in TMD's for vibration control of footbridges, Part 2: numerical analysis and practical realisation. Proceedings of the Design and Dynamic Behaviour of Footbridges, Nov. 20-22, Paris, pp: 214-215.

SETRA/AFGC, 2006. Passarelles piétonnes-Evaluation $\mathrm{du}$ comportement vibratoire sous l'action des piétons (Footbridges-Assessment of dynamic behaviour under the action of pedestrians), Guidelines. Sétra, March.

Van Nimmen, K., G. Lombaert, G. De Roeck and P. Van den Broeck, 2014. Vibration serviceability of footbridges: Evaluation of the current codes of practice. Eng. Struct., 59: 448-461. DOI: 10.1016/j.engstruct.2013.11.006

Venuti, F. and L. Bruno, 2007. An interpretative model of the pedestrian fundamental relation. CR Mecanique, 335: 194-200. DOI: $10.1016 /$ j.crme.2007.03.008

Venuti, F. and L. Bruno, 2009. Crowd-structure interaction in lively footbridges under synchronous lateral excitation: A literature review. Phys. Life Rev., 6: 176-206. DOI: 10.1016/j.plrev.2009.07.001

Zhen, B., W.K. Wong, J. Xu and W. Xie, 2013. Application of Nakamura's model to describe the delayed increase in lateral vibration of footbridges. ASCE J. Eng. Mechan., 139: 1708-1713. DOI: 10.1061/(ASCE)EM.1943-7889.0000579

Živanović, S., A. Pavić and P. Reynolds, 2005. Vibration serviceability of footbridges under human-induced excitation: A literature review. J. Sound Vibrat., 279: 1-74. DOI: 10.1016/j.jsv.2004.01.019

Živanović, S., A. Pavić and E.T. Ingólfsson, 2010. Modeling spatially unrestricted pedestrian traffic on footbridges. ASCE J. Struct. Eng., 136: 1296-1308. DOI: 10.1061/(ASCE)ST.1943-541X.0000226 